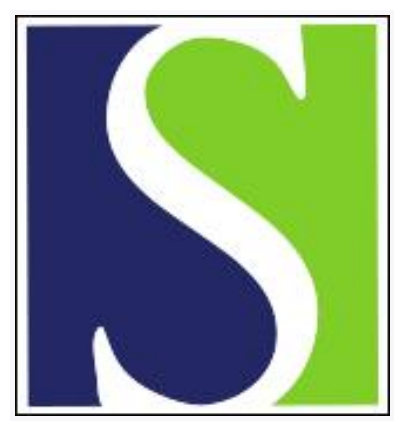

Scand J Work Environ Health 1991;17(3):179-183

https://doi.org/10.5271/sjweh.1713

Issue date: Jun 1991

Effects of asbestos-related pleural disease on pulmonary function.

by Kouris SP, Parker DL, Bender AP, Williams AN

Affiliation: Minnesota Department of Health, Division of Disease Prevention and Control, Minneapolis.

This article in PubMed: www.ncbi.nlm.nih.gov/pubmed/2068556

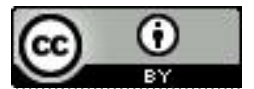




\title{
Effects of asbestos-related pleural disease on pulmonary function
}

\author{
by Steven P Kouris, DO, MPH, David L Parker, MD, MPH, Alan P Bender, DVM, PhD, \\ Allan N Williams, MA, MPH ${ }^{1}$
}

\begin{abstract}
KOURIS SP, PARKER DL, BENDER AP, WILLIAMS AN. Effects of asbestos-related pleural disease on pulmonary function. Scand J Work Environ Health 1991;17:179-83. The relationship between loss of pulmonary function and the presence of asbestos-related pleural disease was evaluated for $913 \mathrm{Min}$ nesota asbestos workers. Asbestos-related pleural disease was categorized as circumscribed plaques or diffuse thickening. Compared with workers with normal pleura, workers with plaques had a decreased mean percentage for predicted forced vital capacity (FVC) and predicted forced expiratory volume in $1 \mathrm{~s}\left(\mathrm{FEV}_{1.0}\right)$. Diffuse thickening was associated with more profound decreases in FVC and $\mathrm{FEV}_{1.0}$. No relationship was seen between FEV $\left.\%\left[\left(100 \times F_{1.0}\right) / F V C\right)\right]$ and either type of pleural disease. Dyspnea was associated with diffuse thickening more so than plaques. These results remained after control for pack-years of smoking, extent of parenchymal disease, and the presence of pulmonary disease history. Pleural plaques and diffuse pleural thickening were considered independent risk factors for the loss of lung function.
\end{abstract}

Key terms: asbestosis, lung function, occupation, pleural plaques.

An increased prevalence of pleural plaque formation has been observed in asbestos-exposed populations $(1-6)$. While asbestos exposure has declined in recent decades the prevalence of pleural plaques appears to be rising, especially among males and older age groups (7). Initially, plaques were regarded as benign markers of past asbestos exposure with no measurable impact on lung function. Subsequently, pleural thickening was identified as potentially deleterious, especially when severe $(8-10)$. These studies, however, included individuals with diffuse pleural thickening, as well as plaques. More recent investigations have attempted to distinguish between the pulmonary effect of plaques and that of diffuse thickening. Restrictive lung disease has since been strongly associated with diffuse pleural thickening $(6,11-13)$. Whether pleural plaques exert a similar effect upon lung function, however, has not been consistently demonstrated (11, 13-17).

Early studies of pleural disease and pulmonary function, in which subtypes of pleural disease (ie, plaques) were not yet discerned, generally found associated decreases in forced vital capacity (FVC) $(10,18,19)$, an effect presumably due to the more severe, diffuse pleural disease. Subsequent to the reclassification of pleural disease by the International Labour Office (ILO) in 1980, investigators began to look at plaques separately from diffuse thickening. Significant

\footnotetext{
1 Minnesota Department of Health, Division of Disease Prevention and Control, Minneapolis, Minnesota, United States.
}

Reprint requests to: Dr DL Parker, Minnesota Department of Health, 717 Delaware Street SE, PO Box 9441, Minneapolis, Minnesota 55440, USA. decreases in FVC, forced expiratory volume in $1 \mathrm{~s}$ $\left(\mathrm{FEV}_{1.0}\right)$, and increased dyspnea were demonstrated to be associated with diffuse pleural thickening (12).

The impact of pleural plaques on pulmonary function has been difficult evaluate. Two early European studies linked restrictive disease with plaques $(14,16)$, but this work was later contradicted by Cotes (11) and, with a much larger study $(\mathrm{N}=386)$, by Gaensler $(15)$, each of whom concluded that plaques had no detrimental effect on lung function. However Järvholm \& Larsson (17), in a study of 130 workers found the presence of plaques to be associated with decreases in FVC, $\mathrm{FEV}_{1.0}$, and increases in mild dyspnea. Schwartz, in a recent study, demonstrated an association between plaques, diffuse thickening, and a restrictive pattern of impairment (13).

The present study was an attempt to address this controversy and to quantitate any adverse effect that diffuse and/or circumscribed pleural lesions have on pulmonary function.

\section{Subjects and methods}

\section{Subjects}

In the fall of 1988, the Minnesota Department of Health conducted a medical screening for former workers, and spouses of workers, at a Minnesota plant that manufactured asbestos-containing ceiling tile and wallboard from 1958 through 1974. Study participants were former workers and spouses who volunteered for free screening. They were made aware of the program either by direct notification by the Department or by extensive radio, television, and newspaper publicity 
about the program. The participants included 1101 former workers and 451 spouses of former workers. Of these 1552 screenees, 996 had worked for the company at some time between 1958 and 1974, when exposure to asbestos occurred. Only data from this asbestos-exposed group are included in the present analysis.

The 996 participants with a history of asbestos exposure consisted of 875 men and 121 women. The mean number of years worked between 1958 and 1974 was 9.4 for the men and 4.4 for the women. The mean age at screening varied from 53.4 for the men to 48.2 for the women. The mean latency (years from first exposure to screening) was 27.0 and 26.8 years for the men and women, respectively. The overall prevalence of any pleural changes was $25.1 \%$.

Table 1 shows worker characteristics by asbestosrelated pleural disease type. Plaques and diffuse thickening were considered asbestos-related if both B readers agreed that the lesion had no other clearly attributable cause (ie, obesity, posttraumatic scarring). Cases in which the $B$ readers felt strongly that factors other than asbestos exposure were responsible for the observed abnormality $(\mathrm{N}=43)$, and individuals with pleural thickening that was seen only in locations other than the chest wall (ie, diaphragmatic) $(\mathrm{N}=39)$, were not included in the further analyses. In addition, one worker who did not participate in the pulmonary function testing was excluded, the total number of workers included in the analysis therefore being 913 .

\section{Radiographs}

Fourteen-by-17-inch (35.6-by-43.2-cm) posteroanterior chest films were taken at maximal inspiration. Two B readers certified by the National Institute for Occupational Safety and Health interpreted all the films independently according to the 1980 ILO classification guidelines (20). In cases of significant disparity $(<10 \%)$, joint review by the radiologists was used to arrive at a consensus. Those films for which consensus could not be reached $(3 \%)$ were averaged, erring on the side of greater severity. After the initial reading, the readers were given a summary of the patients' medical and smoking history, as well as measures of obesity. They were then asked to judge if the pleural and/or parenchymal abnormalities they found were due to asbestos exposure or some other medical condition (ie, postsurgical scarring, congestive heart failure, obesity). A separate opinion was given for pleural and parenchymal changes. For purposes of analysis, this opinion was used to designate pulmonary changes as being either asbestos-related or not asbestos-related.

\section{Spirometry}

Pulmonary function testing was conducted by trained technicians using a Spirotech $\mathrm{S} 400^{\circledR}$. The machines were calibrated twice daily, at the start of each morning and afternoon session. Adjustments were made throughout the day for changes in ambient temperature and barometric pressure. The $\mathrm{FEV}_{1.0}$ and FVC results were considered repeatable if the two best values for each agreed within $5 \%$ or $100 \mathrm{ml}$ (whichever was greater), and the largest values were used as the observed results (21). Since the $87(9 \%)$ workers who did not meet the repeatability requirements had a disproportionate amount of severe pulmonary disease, which may have caused repeatability to become more difficult, these workers were not excluded from the analysis (22). Predicted values based on gender, age, and height for FVC, FEV 1.0 , and FEV \% [(100x $\left.\left.\mathrm{FEV}_{1.0}\right) / \mathrm{FVC}\right]$ were computed using the regression equations of Crapo et al (23).

\section{Physical Examination}

A standardized physical examination of each participant was performed by one of several occupational physicians. It included an examination of the chest and extremities for signs of pulmonary and cardiac disease.

\section{Questionnaire}

A self-administered questionnaire was mailed to the subjects prior to the screening. It included questions regarding medical history (chest injury, surgery, or infection, as well as systemic conditions which commonly have pulmonary manifestations), smoking history (amount, duration, and present usage), presence of respiratory symptoms (cough, dyspnea), and occupational history. The questionnaire was reviewed with each participant at the time of the screening.

\section{Statistical analysis}

Univariate analyses were performed to identify associations between reduced pulmonary function or dyspnea and the presence of pleural plaques, diffuse pleural thickening, interstitial disease, history of pulmonary disease, smoking history, and obesity. A two-sample t-test was used to contrast the pulmonary function values of individuals who had pleural plaques and/or diffuse pleural thickening with individuals who did not have pleural disease. Dyspnea (grade II or greater) was defined as the inability to keep pace because of shortness of breath when walking with others of the same age.

Logistic regression (24) was used to evaluate the relationship between loss in pulmonary function and the presence of plaques, presence of diffuse thickening, interstitial disease $1 / 0$ or greater, pack-years of smoking greater than 40 , and a history of pulmonary disease past or present. Disease outcomes included FVC or $\mathrm{FEV}_{1.0}<80 \%$ of the predicted value, FEV $\%$ $<90 \%$ of the predicted value, and dyspnea grade II or greater. Cut-off points for the spirometric data roughly corresponded to the lower limit of the $90 \%$ confidence interval for these values in a reference population (25). The logistic regression yielded data from which the odds ratios were calculated. 
Table 1. Profile of workers with and without asbestos-related pleural disease $(N=913)$.

\begin{tabular}{|c|c|c|c|c|c|c|c|c|}
\hline \multirow[t]{2}{*}{ Pleural disease } & \multicolumn{2}{|c|}{ Age (years) } & \multicolumn{2}{|c|}{ Exposure $^{a}$} & \multicolumn{2}{|c|}{ Latencyb } & \multicolumn{2}{|c|}{$\begin{array}{l}\text { Pack-years } \\
\text { smoking }\end{array}$} \\
\hline & Mean & SD & Mean & SD & Mean & SD & Mean & SD \\
\hline $\begin{array}{l}\text { None }(N=745) \\
\text { Plaques }(N=146) \\
\text { Diffuse thickening }(N=22)\end{array}$ & $\begin{array}{l}50.5 \\
58.6 \\
61.3\end{array}$ & $\begin{array}{l}11.5 \\
10.9 \\
10.8\end{array}$ & $\begin{array}{r}7.5 \\
12.7 \\
12.3\end{array}$ & $\begin{array}{l}6.0 \\
4.8 \\
4.8\end{array}$ & $\begin{array}{l}26.0 \\
30.3 \\
29.7\end{array}$ & $\begin{array}{l}5.3 \\
1.6 \\
2.6\end{array}$ & $\begin{array}{l}16.3 \\
22.1 \\
29.4\end{array}$ & $\begin{array}{l}18.2 \\
21.0 \\
26.6\end{array}$ \\
\hline
\end{tabular}

a Years worked (1958-1974).

b Years from first exposure to screening examination.

Table 2. Percentage of predicted pulmonary function for workers with asbestos-related pleural plaques and diffuse pleural thickening $(N=913)$. [ $F V C=$ forced vital capacity, $F E V_{1.0}=$ forced expiratory volume in $1 \mathrm{~s}, \mathrm{FEV} \%=\left(100 \times \mathrm{FEV} \mathrm{1}_{1.0}\right) / \mathrm{FVC}, 95 \%$ $\mathrm{Cl}=95 \%$ confidence interval]

\begin{tabular}{|c|c|c|c|c|c|c|}
\hline \multirow{2}{*}{ Pleural disease } & \multicolumn{2}{|c|}{ FVC } & \multicolumn{2}{|c|}{ FEV $_{1.0}$} & \multicolumn{2}{|c|}{ FEV\% } \\
\hline & Mean & $95 \% \mathrm{Cl}$ & Mean & $95 \% \mathrm{Cl}$ & Mean & $95 \% \mathrm{Cl}$ \\
\hline $\begin{array}{l}\text { None }(N=745) \\
\text { Plaques }(N=146) \\
\text { Diffuse thickening }(N=22)\end{array}$ & $\begin{array}{l}92.6 \\
87.6^{a} \\
76.4^{a}\end{array}$ & $\begin{array}{l}91.6-93.6 \\
85.3-90.0 \\
68.6-84.3\end{array}$ & $\begin{array}{l}90.3 \\
84.2^{\mathrm{a}} \\
73.9^{\mathrm{a}}\end{array}$ & $\begin{array}{l}89.1-91.5 \\
81.2-87.1 \\
66.4-81.3\end{array}$ & $\begin{array}{l}97.6 \\
95.9 \\
97.0\end{array}$ & $\begin{array}{l}96.8-98.3 \\
94.0-97.9 \\
92.9-101.1\end{array}$ \\
\hline
\end{tabular}

a $P<0.0005$ (one-tailed $t$-test) compared with normal pleura group.

Table 3. Odds ratios from the logistic regression for predictors of pulmonary impairment. [OR=0dds ratio, $95 \% \mathrm{Cl}=95 \%$ confidence interval of the odds ratio, $F V C=$ forced vital capacity, $\mathrm{FEV}_{1.0}=$ forced expiratory volume in $1 \mathrm{~s}, \mathrm{FEV} \%=(100 \times$ $\left.\left.\mathrm{FEV}_{1.0}\right) / \mathrm{FVC}\right]$

\begin{tabular}{|c|c|c|c|c|c|c|c|c|c|c|}
\hline \multirow{3}{*}{ Outcome variables } & \multicolumn{10}{|c|}{ Predictors } \\
\hline & \multicolumn{2}{|c|}{ Plaques } & \multicolumn{2}{|c|}{$\begin{array}{l}\text { Diffuse } \\
\text { thickening }\end{array}$} & \multicolumn{2}{|c|}{$\begin{array}{c}>40 \text { pack- } \\
\text { years }\end{array}$} & \multicolumn{2}{|c|}{$\begin{array}{c}\text { Interstial } \\
\text { disease } \geq 1 / 0\end{array}$} & \multicolumn{2}{|c|}{$\begin{array}{l}\text { History of } \\
\text { lung disease }\end{array}$} \\
\hline & OR & $95 \% \mathrm{Cl}$ & OR & $95 \% \mathrm{Cl}$ & OR & $95 \% \mathrm{Cl}$ & OR & $95 \% \mathrm{Cl}$ & OR & $95 \% \mathrm{Cl}$ \\
\hline $\begin{array}{l}\text { FVC }<80 \% \text { predicted } \\
\text { FEV } 1.0<80 \% \text { predicted } \\
\text { FEV } \%<90 \% \text { predicted } \\
\text { Dyspnea } \geq \text { grade II }\end{array}$ & $\begin{array}{l}1.5 \\
1.5 \\
0.9 \\
1.0\end{array}$ & $\begin{array}{l}1.0-2.2 \\
1.0-2.2 \\
0.6-1.5 \\
0.7-1.6\end{array}$ & $\begin{array}{l}4.2 \\
4.7 \\
1.0 \\
4.7\end{array}$ & $\begin{array}{l}1.7-10.3 \\
1.8-12.3 \\
0.4-2.8 \\
1.9-11.8\end{array}$ & $\begin{array}{l}2.5 \\
3.5 \\
3.7 \\
2.1\end{array}$ & $\begin{array}{l}1.6-4.0 \\
2.2-5.6 \\
2.3-5.9 \\
1.3-3.4\end{array}$ & $\begin{array}{l}1.8 \\
2.2 \\
2.0 \\
1.7\end{array}$ & $\begin{array}{l}1.2-2.7 \\
1.4-3.3 \\
1.3-3.1 \\
1.1-2.6\end{array}$ & $\begin{array}{l}1.4 \\
2.0 \\
1.9 \\
2.5\end{array}$ & $\begin{array}{l}1.0-1.9 \\
1.4-2.7 \\
1.3-2.7 \\
1.7-3.6\end{array}$ \\
\hline
\end{tabular}

\section{Results}

Table 2 displays the mean spirometric values for the workers with normal-appearing pleura, asbestos-related pleural plaques, and asbestos-related diffuse pleural thickening. Significant decreases in the mean FVC and $\mathrm{FEV}_{1.0}$, but not FEV \%, were seen in the presence of pleural disease, the greatest decline occurring among those with diffuse thickening. Similar results were consistently demonstrated after stratification by pack-years of smoking (never, 1-39, and $\geq 40$ ), or interstitial disease (none, grade $1 / 0-1 / 2$, and grade $2 / 1$ or greater). While decrements in FVC and $\mathrm{FEV}_{1.0}$ were still evident among the workers with pleural disease who never smoked and did not have interstitial disease, statistical significance was lost due to the small numbers. The prevalence of interstitial disease $(1 / 0$ or greater) was $14 \%$.

The presence of dyspnea was also examined by pleural disease categories. The mean prevalence for grade II dyspnea or greater was $16.8 \%$ in the absence of pleural disease, $22.8 \%$ among those with plaques, and $59.1 \%$ among the workers with diffuse changes.
Within each of these strata, the prevalence rose dramatically in a stepwise fashion with increasing packyears of smoking. A similar pattern was seen with dyspnea, grade I or more.

Table 3 shows the odds ratios resulting from the logistic regression for the five predictors of impaired pulmonary function (pleural plaques, diffuse pleural thickening, pack-years of smoking, interstitial disease, and pulmonary history). Pleural plaques were associated with nonsignificant decreases in FVC and FEV $_{1.0}$. No relationship was seen with FEV \%. Diffuse pleural disease was significantly associated with declines in the FVC and $\mathrm{FEV}_{1.0}$, as well as with the occurrence of dyspnea. Once again, no relationship was found with FEV \%. Pack-years, interstitial disease, and pulmonary history each had a moderate impact on all the outcomes.

It was noted that the magnitude of the effect that plaques had on FVC and $\mathrm{FEV}_{1.0}$ was modified by whether the worker had a history of pulmonary disease. When this history was present, the additional presence of plaques did not significantly increase an 
individual's risk of impairment, but for those individuals with no history of pulmonary disease $(\mathrm{N}=655)$, plaques had a much greater effect. For FVC the odds ratio equaled 2.1 [95\% confidence interval $(95 \%$ CI) 1.2-3.5], and for $\mathrm{FEV}_{1.0}$ it was $1.7(95 \% \mathrm{CI}$ 1.0-2.9).

\section{Discussion}

The findings of the present study indicate that pleural plaques are associated with small decrements in FVC and $\mathrm{FEV}_{1,0}$ and the preservation of the FEV \%, consistent with restrictive lung disease. A similar, but more substantial, effect was demonstrated among the few workers who had diffuse pleural thickening. These findings remained significant when the effects of smoking history, coexisting interstitial disease, and the presence of other medical conditions were controlled for.

Previously investigators who attempted to account for the influence of smoking generally classified workers by current (or recent) smoking status. We chose to consider cumulative pack-years of smoking, regardless of current status, as a more valid criterion since it has been shown that smoking cessation does not substantially reverse the reductions in lung function associated with long-term usage $(26,27)$. This procedure resulted in more homogeneous groupings of workers and allowed the effects of the other variables, particularly the subtle effects of plaques, to be more easily distinguished from the effects of smoking.

The $\mathrm{B}$ reading procedure was modified to allow the radiologists to consider clinical factors before rendering an opinion regarding likely etiology. This modification was made by the Minnesota Department of Health (28) in an attempt to increase the sensitivity and specificity of the diagnosis of asbestos-related pleural disease. By excluding pleural abnormalities which were thought to be due to factors other than asbestos exposure, we felt that a more precise estimate of risk for asbestos-related disease could be attained. The inclusion of workers with pleural disease unrelated to asbestos exposure could have produced risk estimates more representative of these other conditions. The lung function of 28 workers with plaques who were excluded from the analysis did not differ greatly from that of the workers who were included, although a slightly greater obstructive component was noted. These workers were also slightly older and much heavier, with more pack-years of smoking, more interstitial disease, and more dyspnea. Conversely, the 15 workers with diffuse thickening who were excluded had much worse pulmonary function, particularly obstructive disease, and less severe interstitial disease than those who were included, but they did not differ with regard to other characteristics.

While the logistic regression model fit the data well, there remained a considerable amount of variability in the observed disease pattern that was not accounted for. There are three possible explanations for this oc- currence. First, there were factors present, such as obesity or past medical history, which may have influenced the $B$ readers' interpretation of radiologic changes of the pleura (29). In the present study, workers with either of these two factors were more likely to have had their pleural abnormalities judged as being unrelated to asbestos exposure. It is unknown to what extent asbestos-related abnormalities were judged to be nonasbestos-related. If this type of judgment did occur, the result would be an underestimate of the risk for those with asbestos-related pleural disease. Similarly, the slightly weaker effects of both pleural plaques and diffuse thickening among heavy smokers may have reflected a bias towards dismissing the pleural abnormalities of heavy smokers as being smoking-related as opposed to asbestos-related. Second, the presence of asbestos-related subroentgenologic fibrosis coexisting with, and perhaps preceding the recognition of, pleural disease has frequently been theorized as the true cause of pleural-associated restrictive disease $(13,17,30)$. While this is a plausible theory, it remains rather difficult to prove. If this were a cause for pulmonary impairment and it did precede other radiographic changes, it could cause diminution of the risk estimates for radiographic changes through misclassification of abnormal individuals as normal. We investigated this issue by examining the effects of exposure duration and latency among nonsmoking workers with normal radiographs. Pulmonary decline was not readily apparent in this small sample when it was compared with that of workers with less latency and less exposure. Finally, a certain amount of imprecision is inherently associated with the use of predicted values for spirometric data. Age, height, and gender adjustments have typically accounted for no more than 70 to $80 \%$ of the variance in spirometric values of normal populations (23).

Dyspnea, an indirect and somewhat subjective measure of functional impairment, yielded results approximating those of the spirometry. Consistent with the findings of previous studies, a high correlation was found between spirometric values and the level of dyspnea reported in the questionnaire. Dyspnea was associated with diffuse disease more than plaques and, as expected, increased in severity with increasing packyears, interstitial disease, and history of lung disease.

In conclusion, it appears that asbestos-related plaques and diffuse pleural thickening are associated with measurable decreases in pulmonary function. Further study, however, is necessary to determine the mechanism involved in this process and the long-term clinical implications of these findings.

\section{Acknowledgments}

This work was completed while Dr Kouris was a resident at the Midwest Center for Occupational Health \& Safety, St Paul Ramsey Medical Center, assigned to the Minnesota Department of Health. 


\section{References}

1. Albeda SM, Epstein DM, Gefter WB, Miller WT. Pleural thickening: its significance and relationship to asbestos dust exposure. Am Rev Respir Dis 1982;126:621-4.

2. Anderson HA, Selikoff IJ. Pleural reactions to environmental agents. Fed Proc 1978;37:24962500.

3. Anderson HA, Lilis R, Daum SM, Selikoff IJ. Asbestosis among household contacts of asbestos factory workers. Ann NY Acad Sci 1978;330:387-99.

4. Hillerdal G. Pleural plaques: occurrence, exposure to asbestos and clinical importance [Doctoral dissertation]. Uppsala (Sweden): Uppsala University, 1980.

5. Hilt B, Lein JT, Lund-Larsen PG. Lung function and respiratory symptoms in subjects with asbestos-related disorders: a cross-sectional study. Am J Ind Med 1987; 11:517-28.

6. McLoud TC, Woods BO, Carrington CB, Epler GR, Gaensler EA. Diffuse pleural thickening in an asbestosexposed population: prevalence and causes. Am J Roentgenol 1985;144:9-18.

7. Zitting AJ, Kuusela T, Impivaara 0, Maatela J, Aromaa A. Prevalence of radiographic small lung opacities and pleural abnormalities in a representative sample of adult Finns [Abstract]. In: International Labour Office (ILO). VIIth International Pneumoconioses Conference Proceedings. Pittsburgh: ILO, 1988:99.

8. Arzt GH, Pirtkien R, Rosenthal $\mathrm{H}$. Review of lung function data in 195 patients with asbestosis of the lung. Int Arch Occup Environ Health 1980;45:63-79.

9. Cookson WO, Musk AW, Glancy JJ. Pleural thickening and gas transfer in asbestosis. Thorax 1983;38:657-61.

10. Rom W, Thornton J, Miller A, Lilis R, Selikoff IJ. Abnormal spirometry in shipyard workers with pleural disease [Abstract]. Am Rev Respir Dis 1977;115:239.

11. Cotes JE, King B. Relationship of lung function to radiographic reading (ILO) in patients with asbestos related lung disease. Thorax 1988;43:777-83.

12. McGavin CR, Sheers G. Diffuse pleural thickening in asbestos workers: disability and lung function abnormalities. Thorax 1984;39:604-7.

13. Schwartz DA, Fuortes LJ, Galvin JR, et al. Asbestosinduced pleural fibrosis and impaired lung function. Am Rev Respir Dis 1990;141:321-6.

14. Fridriksson HV, Hedenstrom $\mathrm{H}$, Hillerdale G, et al. Increased lung stiffness in persons with pleural plaques. Eur J Respir Dis 1981;62:412-24.

15. Gaensler EA, Jederlinic PJ, McLoud TC. Lung function with asbestos-related circumscribed pleural plaques [Abstract]. International Labour Office (ILO): VIIth International Pneumoconioses Conference Proceedings. Pittsburgh, PA: ILO, 1988;70.

16. Hedenstierna G, Alexandersson R, Kolmodin-Hedman
B, Szamosi A, Tollqvist J. Pleural plaques and lung function in construction workers exposed to asbestos. Eur J Respir Dis 1980;2:111-22.

17. Järvholm B, Larsson S. Do pleural plaques produce symptoms? A brief report. J Occup Med 1988;30:34547.

18. Becklake MR, Fournier-Massey G, McDonald JC, Siemiatychi J. Rossiter CE. Lung function in relation to chest radiographic changes in Quebec asbestos workers: I. methods, results and conclusions. Bull Physio-Pathol Respir 1970;6:637-59.

19. Britton MG. Asbestos pleural disease. Br J Dis Chest 1982;76:1-10.

20. International Labour Office (ILO). Guidelines for the use of ILO international classification of radiographs of pneumoconioses. Geneva: ILO, 1980. (Occupational safety and health series; no 22.)

21. American Thoracic Society. ATS statement - snowbird workshop on standardization of spirometry. Am Rev Respir Dis 1979;831-8.

22. Eisen EA, Oliver LC, Christiani DC, Robins JM, Wegman DH. Effects of spirometry standards in two occupational cohorts. Am Rev Respir Dis 1985;132:120-24.

23. Crapo RO, Morris AH, Gardner RM. Reference spirometric values using techniques and equipment that meet ATS requirements. Am Rev Respir Dis 1981;123: $659-64$.

24. Kleinbaum DG, Kupper LL, Morganstern H. Modeling: theoretical considerations. In: Lifetime Learning Publications. Epidemiologic research. Belmont CA: Lifetime Learning Publications, 1982;419-46.

25. Pennock BE, Cottrill JJ, Rogers RM. Pulmonary function testing: what is "normal"? Arch Intern Med 1983; $143: 2123-27$

26. Friedman GD, Siegelaub AB. Changes after quitting cigarette smoking. Circulation 1980;61:716-23.

27. Higenbottam T, Clark TJH, Shipley MJ, Rose G. Lung function and symptoms of cigarette smokers related to tar yield and number of cigarettes smoked. Lancet 1980; 2:409-12.

28. Minnesota Department of Health. Medical screening for asbestos-related lung disease among Conwed Corporation (Cloquet) workers and their spouses. Minneapolis, MN: Minnesota Department of Health, 1989.

29. Parker DL, Bender AP, Hankinson S, Aeppli D. Public health implications of the variability in the interpretation of 'B' readings for pleural changes. J Occup Med 1989;31:775-80.

30. Zedda S, Aresini G, Ghezzi I, Sartorelli E. Lung function in relation to radiographic changes in asbestos workers. Respiration 1973;30:132-40.

Received for publication: 3 July 1990 